\title{
Influência da secagem do pequi (Caryocar brasiliense Camb.) na qualidade do óleo extraído
}

\author{
Influence of pequi drying (Caryocar brasiliense Camb.) on the quality of the oil extracted
}

Ludmila Pereira AQUINO $^{1 \star}$, Fabiana Queiroz FERRUA ${ }^{1}$, Soraia Vilela BORGES ${ }^{1}$, Rosemar ANTONIASSI ${ }^{2}$, Jefferson Luiz Gomes CORREA ${ }^{1}$, Marcelo Angelo CIRILLO ${ }^{3}$

\begin{abstract}
Resumo
O pequi (Caryocar brasiliense Camb. ) tem se destacado por ser um fruto oleaginoso e rico em carotenoides. A secagem é um processo utilizado na extração do óleo por hexano, mas a degradação dos carotenoides e óleo podem ocorrer. O objetivo deste trabalho foi avaliar a influência de diferentes métodos de secagem (ao sol, estufa ventilada a 40 e a $60^{\circ} \mathrm{C}$ ) e do tempo ( 4 horas e até peso constante) no rendimento e na qualidade do óleo extraído por hexano no extrator Soxhlet. Quando a polpa de pequi foi seca, 3\% ou conteúdo menor de umidade e maior rendimento do óleo foi obtido ( 52 a 59\%, base seca). Carotenoides totais foram maiores e índice de peróxido menores para a polpa desidratada a $40{ }^{\circ} \mathrm{C}$ em estufa ventilada, quando comparada com a secagem da polpa em estufa a $60{ }^{\circ} \mathrm{C}$ e ao sol. Estes resultados indicaram que a secagem em estufa a $40^{\circ} \mathrm{C}$ por 19 horas resultou num maior rendimento do óleo e menor degradação térmica.

Palavras-chave: Caryocar brasiliense Camb.; desidratação; extração sólido-líquido; óleo.
\end{abstract}

\begin{abstract}
Pequi (Caryocar brasiliense Camb) has stood out for being an oleaginous fruit rich in carotenoids. Drying is widely used technique in the oil extraction process using hexane, but the degradation of oil and carotenoids may occur. The objective of this study was to evaluate the influence of different drying methods (sun, air-circulated drier at 40 and $60{ }^{\circ} \mathrm{C}$ ) and time (4 hours and up to constant weight) on the yield and quality of the oil extracted using hexane using a soxhlet apparatus. When the pequi pulp was dried up to $3 \%$ or even lower, more oil yield was obtained (52-59\%, dry basis). The total carotenoids contents obtained were higher and the peroxide index was lower for the pulp dried at $40{ }^{\circ} \mathrm{C}$ in an air-circulated drier when compared to drying at $60^{\circ} \mathrm{C}$ in an air-ventilated drier and to sun drying technique. These results indicate that drying in an air-circulated drier at $40^{\circ} \mathrm{C}$ for 19 hours resulted in higher oil yields with less heat degradation.

Keywords: Caryocar brasiliense Camb.; dehydration; solid-liquid extraction; oil.
\end{abstract}

\section{Introdução}

O pequi é um fruto sazonal com safra entre os meses de novembro e fevereiro, dependendo da região (LORENZI, 2000). Por ser fonte de renda da população do cerrado, pesquisadores têm desenvolvido projetos voltados para o processamento da polpa de pequi e a fabricação de conservas, além do congelamento tradicional da polpa (LIMA, 2006), com o objetivo de diminuir a deterioração e a descaracterização do sabor da polpa.

O pequi é rico em carotenoides (AZEVEDO-MELEIRO; RODRIGUEZ-AMAYA, 2004; LIMA, 2006; OLIVEIRA et al., 2006; SILVA; SOARES; HELOU, 1993), que possuem importantes funções biológicas no ser humano, atuando na prevenção de alguns tipos de câncer, na inibição das mucosas contra úlceras gástricas, na capacidade de prevenir a fotossensibilização em certas doenças de pele, no aumento da resposta imunológica a determinados tipos de infecção e nas propriedades antienvelhecimento
(COLDITZ et al., 1985; RODRIGUEZ-AMAYA, 1985; OLSON, 1989). Além disso, alguns carotenoides apresentam atividade como vitamina A (RAMOS, 1991; RODRIGUEZ-AMAYA, 1993a) e protetores de óleos e gorduras, por serem considerados sequestradores de oxigênio, oxidando-se preferencialmente (RODRIGUEZ-AMAYA, 1993b).

Cuidados especiais com relação aos métodos de processamento e armazenamento de alimentos devem ser levados em conta devido à grande instabilidade dos carotenoides. Por causa de seu alto grau de insaturação, são susceptíveis à isomerização e oxidação (O' BRIEN, 2004; RAMOS, 1991; RODRIGUEZ-AMAYA, 1993b). A exposição dos carotenoides ao calor, ao oxigênio, à luz, acidez elevada e à baixa atividade de água são fatores que podem levar a mudanças estruturais, reduzindo assim sua atividade (RODRIGUEZ-AMAYA, 1993b).

Recebido para publicação em 27/9/2007

Aceito para publicação em 22/1/2008 (002887)

${ }^{1}$ Departamento de Ciência dos Alimentos, Universidade Federal de Lavras - UFLA, Campus Universitário, CP 3037, CEP 37200-000, Lavras - MG, Brasil,

E-mails: lpereiraaquino@yahoo.com.br,sborges@ufla.br,fqueiroz@ufla.br, jefferson@ufla.br

${ }^{2}$ Laboratório de Óleos e Gorduras, Embrapa Agroindústria de Alimentos, Rio de Janeiro - RJ, Brasil, E-mail: rosemar@ctaa.embrapa.br

${ }^{3}$ Departamento de Estatística, Universidade Federal de Lavras - UFLA, Campus Univsersitário, Lavras - MG, Brasil, E-mail: marcelocirillo@hotmail.com

${ }^{*}$ A quem a correspondência deve ser enviada 
A secagem é considerada um processamento prejudicial aos carotenoides, pois a quantidade de água é crítica na sua estabilidade. Por outro lado, uma pequena quantidade de água em um alimento desidratado age como barreira para o oxigênio, aumentando sua estabilidade e consequentemente sua vida de prateleira (FENNEMA, 2006).

Na extração de óleo, a secagem de grãos e frutos é uma prática usual que facilita o processo no que diz respeito ao contato entre o solvente e o soluto (óleo) a ser extraído, resultando em maiores rendimentos (TANGO; CARVALHO; SOARES, 2004).

Neste processo, a temperatura é um dos fatores mais importantes, podendo afetar as propriedades fisico-químicas do óleo, levar à rancificação de gorduras e alterar pigmentos, tais como os carotenoides, quando submetidos a altas temperaturas (BIAGI; VALENTINI; QUEIROZ, 1992; NOGUEIRA, 1992). Dessa forma, a seleção das condições de operação (tipo de secagem e tempo) que minimizam essas alterações é importante para obtenção de produtos de qualidade.

Alguns métodos analíticos são utilizados para analisar a qualidade do óleo extraído e caracterizá-lo do ponto de vista funcional e de conservação. Dentre estes se destacam o teor de ácidos graxos livres e o índice de peróxido. Outra análise importante é a avaliação da perda de carotenoides, que, por serem muito instáveis, indicam o quão prejudicial foi o processamento (ROSSELL; PRITCHARD, 1991).

Este trabalho teve por objetivo avaliar o efeito do método e tempo de secagem sobre o teor de óleo extraído e sua qualidade físico-quimica (teor de ácidos graxos livres e índice de peróxido), além do teor de carotenoides totais presentes no óleo.

\section{Material e métodos}

\subsection{Matéria-prima}

Os pequis (Caryocar brasiliense Camb.) foram provenientes do município de Cordisburgo (MG), no período de safra (janeiro de 2006). Foram selecionados frutos não danificados e maduros.

\subsection{Preparo das amostras}

Os frutos de pequi foram lavados em água corrente, submersos em solução de hipoclorito de sódio a $50 \mathrm{mg} \cdot \mathrm{kg}^{-1}$ por cinco minutos e, após esse período, descascados. Em seguida, os pequis foram despolpados manualmente com faca de aço inoxidável, cortados em lascas de $0,3 \mathrm{~cm}$ de espessura, $1,6 \mathrm{~cm}$ de largura e 2,8 cm de comprimento, e congelados em sacos plásticos até a realização dos experimentos.

\subsection{Caracterização da matéria-prima}

O teor de umidade da polpa de pequi congelada em lascas foi realizado de acordo com o método AOCS Bc 2-49 (1997).

\subsection{Planejamento experimental}

A polpa de pequi em lascas foi submetida a seis tratamentos de secagem aleatorizados com seis repetições para cada tratamento:

$$
\begin{aligned}
& \text { T1 - secagem ao sol por } 4 \text { horas; } \\
& \text { T2 - secagem ao sol por } 12 \text { horas; } \\
& \text { T3 - secagem em estufa a } 40^{\circ} \mathrm{C} \text { por } 4 \text { horas; } \\
& \text { T4 - secagem em estufa a } 40^{\circ} \mathrm{C} \text { por } 19 \text { horas; } \\
& \text { T5 - secagem em estufa a } 60^{\circ} \mathrm{C} \text { por } 4 \text { horas; e } \\
& \text { T6 - secagem em estufa a } 60^{\circ} \mathrm{C} \text { por } 16 \text { horas. }
\end{aligned}
$$

Nos tempos adotados nos tratamentos T2, T4 e T6 obteve-se peso constante do pequi no processo de secagem.

A polpa de pequi foi colocada em bandejas de aço inox perfuradas e seca em estufa com circulação de ar (marca: Fanem). A secagem ao sol foi realizada utilizando-se estas bandejas, as quais foram colocadas sobre um suporte de madeira apropriado. A temperatura média e a umidade relativa do ar no dia do experimento foram de $28{ }^{\circ} \mathrm{C}$ e $55 \%$.

Após a secagem o material foi triturado em multiprocessador Britânia por 1 minuto, sendo as amostras da polpa submetidas às análises do teor de umidade e à extração do óleo.

\subsection{Extração do óleo}

Na extração do óleo utilizou-se a metodologia de Soxhlet com emprego de hexano como solvente (reagente PA da Proquímios), no período de 4 horas de extração. O rendimento de óleo foi expresso em porcentagem ( $\mathrm{g}$ de óleo/100 g de amostra seca).

\subsection{Análises físico-químicas do óleo}

Foram realizadas análises do teor de ácidos graxos livres (AGL), expresso em \% de ácido oleico e índice de peróxido (IP), segundo as metodologias Ca 5a 40 e Cd 8 53, respectivamente da AOCS (1997).

\subsection{Análise do teor de carotenoides}

A análise do teor de carotenoides totais do óleo foi realizada através da leitura das amostras no espectro visível a $452 \mathrm{~nm}$ (Espectrofotômetro BECKAM DU 70), utilizando hexano, grau espectrofotométrico, como solvente e feito os cálculos de carotenoides totais com valor de extinção de 2500, sugerido por Davies (1976).

\subsection{Análise estatística}

Para estudar as médias dos tratamentos considerando as variáveis respostas - teor de umidade final da polpa, rendimento do óleo, os parâmetros físico-químicos do óleo (AGL, IP) e teor de carotenoides totais - foram realizadas análises de variância (nível de significância de 5\%). Para estas variáveis, na quais foram detectadas diferenças significativas, foi utilizado o teste de Tukey para identificar quais tratamentos diferiram significativamente entre si (GOMES, 1990).

As análises estatísticas foram realizadas com o programa estatístico SISVAR (FERREIRA, 2000).

\section{Resultados e discussão}

$\mathrm{Na}$ Tabela 1 encontram-se os valores médios de umidade final (\% em base seca) e o teor de óleo extraído (\% em base seca), bem como algumas propriedades físico-químicas e o teor de carotenoides do óleo para os seis tratamentos. 
Tabela 1. Teor de umidade e de óleo do pequi desidratado e características físico-químicas do óleo.

\begin{tabular}{|c|c|c|c|c|c|}
\hline Tratamento & $\begin{array}{l}\text { Teor de umidade } \\
\text { final (\% bs) }\end{array}$ & $\begin{array}{c}\text { Teor de óleo } \\
(\% \text { bs })\end{array}$ & $\begin{array}{c}\text { AGL } \\
\text { (\% de ácido oleico) }\end{array}$ & $\begin{array}{l}\text { IP }\left(\text { meq } \mathrm{O}_{2} / \mathrm{kg} \text { de }\right. \\
\text { amostra })\end{array}$ & $\begin{array}{c}\text { Teor de carotenoides } \\
\left(\mathrm{mg}^{\left.-\mathrm{kg}^{-1}\right)}\right.\end{array}$ \\
\hline $\mathrm{T} 1$ & $10,37^{\mathrm{b}}$ & $42,5^{c, d}$ & $0,69^{c}$ & $47,17^{\mathrm{a}}$ & $8,54^{c}$ \\
\hline $\mathrm{T} 2$ & $2,93^{\mathrm{d}}$ & $59,0^{\mathrm{a}}$ & $0,65^{\mathrm{c}}$ & $45,45^{\mathrm{a}}$ & $14,50^{c}$ \\
\hline $\mathrm{T} 3$ & $20,53^{a}$ & $46,0^{c}$ & $1,03^{\mathrm{a}}$ & $4,47^{c}$ & $213,75^{\mathrm{a}}$ \\
\hline $\mathrm{T} 4$ & $0,96^{\mathrm{d}}$ & $52,2^{\mathrm{b}}$ & $1,09^{\mathrm{a}}$ & $1,24^{\mathrm{c}}$ & $246,70^{\mathrm{a}}$ \\
\hline T5 & $7,41^{\mathrm{c}}$ & $39,1^{\mathrm{d}}$ & $0,70^{c}$ & $8,09^{c}$ & $111,99^{\mathrm{b}}$ \\
\hline T6 & $1,36^{\mathrm{d}}$ & $59,4^{\mathrm{a}}$ & $0,82^{\mathrm{b}}$ & $22,19^{b}$ & $10,45^{\mathrm{c}}$ \\
\hline
\end{tabular}

${ }^{*}$ Médias seguidas da mesma letra minúscula, na coluna, são iguais entre si pelo teste de Tukey (5\% de significância).

Observa-se que maiores teores de óleos foram obtidos nas condições de maior tempo de secagem para quaisquer temperaturas, devido ao reduzido teor de água, o qual aumenta o poder de extração dos solventes apolares. Tendência similar foi observada por Ramos (1987); Silva e Turatti (1991); Guarte, Muhlbauer e Kellert (1996) e Tango, Carvalho e Soares (2004), na extração de óleo de diferentes matérias-primas. Além disso, a secagem promove o rompimento da estrutura celular do tecido liberando com maior facilidade os compostos intracelulares (LEWICKI; PAWLAK, 2003).

Portanto, a secagem ou tostagem constitui uma etapa prévia para aumentar a recuperação do óleo e sua qualidade, sendo objeto de otimização na extração de óleos de sementes oleaginosas, pois pode provocar efeitos adversos sobre sua qualidade. Altas temperaturas, longo tempo de exposição a tratamentos térmicos, irradiações e alta concentração de oxigênio, levam à oxidação lipídica e afetam suas propriedades físico-químicas (RAMESH et al., 1995).

Quanto à acidez, nos óleos provenientes de frutos que apresentam alta umidade, e ainda no caso do pequi em que o fruto foi coletado após queda da planta, é esperado que ocorra a hidrólise enzimática pela presença de lipases, hidrolisando os triacilgliceróis e liberando ácidos graxos livres. Ainda assim, os resultados obtidos são inferiores à acidez normalmente encontrada em óleos brutos de palma, que normalmente apresentam acidez acima de $1 \%$ de ácidos graxos livres (GUNSTONE; HARWOOD; PADLEY, 1994). Verificou-se que o tempo de secagem não influenciou a acidez do óleo para os tratamentos realizados ao sol e a $40^{\circ} \mathrm{C}$. Para a temperatura de $60^{\circ} \mathrm{C}$ houve efeito significativo do tempo e a diferença de AGL para os dois tratamentos pode estar relacionada à exposição do pequi a altas temperaturas por um longo tempo.

Resultados similares foram encontrados por Adeeko e Ajibola (1990) no estudo da obtenção de óleo de amendoim em diferentes temperaturas e tempo de secagem. Já para óleos obtidos de outras fontes a variação de tempo e temperatura não afetou a \% de AGL (GUARTE; MUHLBAUER; KELLERT , 1996; GHALY; SUTHERLAND, 1983; 1984).

Quanto à oxidação do óleo, foi observado maior índice de peróxidos para os óleos provenientes da secagem ao sol em virtude da luz e do oxigênio do ar. A secagem à temperatura de $60^{\circ} \mathrm{C}$ e 16 horas (em estufa com circulação de ar, mas no escuro) também promoveu deterioração do óleo, mas menor que a ocorrida na secagem ao sol. É esperado que altas temperaturas, presença de oxigênio, luz, presença de metais, enzimas, metaloproteínas, entre outros promovam a deterioração do óleo. Os menores valores para o índice de peróxido foram obtidos nos tratamento realizados à temperatura de $40{ }^{\circ} \mathrm{C}$, independente do tempo utilizado, e a $60^{\circ} \mathrm{C}$ por 4 horas.

Convém salientar que valores acima de $15 \mathrm{meq}_{2} / \mathrm{kg}$ não podem ser utilizados para o consumo humano (ANVISA, 2005) e, neste caso, o óleo bruto obtido através da secagem da polpa de pequi a $60^{\circ} \mathrm{C}$ por 16 horas e ao sol pode ser considerado de má qualidade.

Adeeko e Ajibola (1990) observaram que o índice de peróxido do óleo de amendoim aumentou com a temperatura e o tempo de secagem.

Ghaly e Sutherland (1983), no estudo da secagem da soja, verificaram que o índice de peróxido do óleo bruto aumentou em temperaturas acima de $50^{\circ} \mathrm{C}$.

Foi observado que ocorreu maior retenção de carotenoides no óleo de pequi obtido após os tratamentos de secagem a $40{ }^{\circ} \mathrm{C}$, independente do tempo de secagem, resultando em teores significativamente maiores que os demais $(\mathrm{p}<0,05)$. A secagem à temperatura de $60^{\circ} \mathrm{C}$ por 16 horas e a secagem ao sol promoveram praticamente a destruição dos carotenoides do óleo de pequi. Estes valores estão próximos ao encontrado por Ramos et al. (2001) para a polpa de pequi crua $\left(231,09 \mu \mathrm{g} \cdot \mathrm{g}^{-1}\right)$. De forma semelhante, Ramos (1987) verificou uma maior perda de carotenoides totais no pequi com o aumento da temperatura de secagem. Mariano et al. (2006) observaram perdas de betacaroteno $(30,83,32,00$ e $43,90 \%)$ em pequi com o aumento da temperatura ao desidratá-lo nas temperaturas de 60,70 e $105^{\circ} \mathrm{C}$, respectivamente

$\mathrm{Na}$ secagem ao sol, foram obtidos valores menores de carotenoides, independente do tempo de secagem, e isto é devido ao possível efeito dos raios ultravioletas e presença do oxigênio na degradação dos carotenoides.

Segundo Ramos (1987), a perda de carotenoides é mais afetada na presença de oxigênio do que na temperatura de secagem. Este fato foi confirmado nos resultados deste experimento que revelaram menores teores de carotenoides para o pequi seco ao sol, portanto exposto a maiores quantidades de oxigênio.

\section{Conclusão}

De acordo com as condições operacionais empregadas neste experimento concluiu-se que a secagem da polpa de pequi em estufa a $40{ }^{\circ} \mathrm{C}$ foi o melhor método de preservação das características do fruto, devido à maior retenção de carotenoides durante o pré-tratamento da polpa de pequi e menor índice de peróxido do óleo extraído com hexano. Além disso, como o 
maior rendimento de óleo se deu com o maior tempo de secagem, pode-se dizer que o tempo de 19 horas para a secagem da polpa de pequi é o mais viável.

\section{Agradecimentos}

À CAPES (Coordenação de Aperfeiçoamento de Pessoal de Nível Superior) pela concessão de Bolsa de Mestrado e à FAPEMIG (Fundação de Amparo à Pesquisa do Estado de Minas Gerais) pelo financiamento.

\section{Referências bibliográficas}

ADEEKO, K. A.; AJIBOLA, O. O. Processing factors affecting yield and quality of mechanically expressed groundnut oil. Journal of Agricultural Engineering Research, v. 45, p. 31-43, 1990.

AMERICAN OIL CHEMISTS' SOCIETY - AOCS. Official methods and recommended practices. Champaign, 1997.

AGÊNCIA NACIONAL DE VIGILÂNCIA SANITÁRIA - ANVISA. Resolução RDC n. 270, de 22 de setembro de 2005. Regulamento Técnico para Óleos Vegetais, Gorduras Vegetais e Creme Vegetal. Diário Oficial da União, Brasília, 23 de Setembro de 2005.

AZEVEDO-MELEIRO, C. H.; RODRIGUEZ-AMAYA, D. B. Confirmation of the identify of the carotenoids of tropical fruits by HPLC-DAD and HPLC-MS. Journal of Food Composition and Analysis, v. 17, n. 3-4, p. 385-396, 2004.

BIAGI, J. D.; VALENTINI, S. R. T.; QUEIROZ, D. M. Secagem de Produtos Agrícolas. In: CORTEZ, L. A. B.; MAGALHÃES, P. S. G. (Eds.). Introdução a Engenharia Agrícola. Campinas: Unicamp, 1992. p. 245-265.

COLDITZ, G. A. et al. Increased green and yellow vegetable intake and lowered cancer death in an elderly population. American Journal of Clinical Nutrition, v. 41, p. 32-36, 1985.

DAVIES, B. H. Carotenoids. In: GOODWIN, T. W. (Ed.). Chemistry and Biochemistry of Plant Pigments. London: Academic Press, 1976. p. 38-165.

FENNEMA, O. R. Fennema's Food Chemistry (Food Science and Technology). London: CRC Press, 2006.

FERREIRA, D. F. Análises estatísticas por meio do SISVAR (Sistema para Análise de Variância) para Windows 4.0. In: REUNIÃO ANUAL DA REGIÃO BRASILEIRA DA SOCIEDADE INTERNACIONAL DE BIOMETRIA, 2000, São Carlos. Anais... São Carlos: UFSCar, 2000, p. 255-258.

GHALY, T. F.; SUTHERLAND, J. W. Quality aspects of heated-air drying of soybeans. Journal of Stored Products Research, v. 19, n. 1, p. 31-41, 1983.

GHALY, T. F.; SUTHERLAND, J. W. Heat damage to grain and seeds. Journal of Agricultural Engineering Research, v. 30, p. 337-345, 1984.

GOMES, F. P. Curso de estatística experimental. São Paulo: Nobel, 1990.

GUARTE, R. C.; MUHLBAUER, W.; KELLERT, M. Drying characteristics of copra and quality of copra and coconut oil. Postharvest Biology and Technology, v. 9, n. 3, p. 361-372, 1996.

GUNSTONE, F. D.; HARWOOD, J. L.; PADLEY, F. B. The Lipid Handbook. London: Chapman \& Hall, 1994. 551 p.

LEWICKI, P. P.; PAWLAK, G. Effect of drying on microstructure of plant tissue. Drying Technology, v. 21, n. 4, p. 657-683, 2003.

LIMA, A. Ouro do Cerrado. Revista Minas faz Ciência, n. 27, p. 38-41, 2006.
LORENZI, H. Árvores brasileiras: manual de identificação e cultivo de plantas arbóreas nativas do Brasil. Nova Odessa: Plantarum, 2000.

MARIANO, R. G. et al. Comparação da perda percentual de beta-caroteno no pequi (Caryocar brasiliense) desidratado a $60^{\circ} \mathrm{C}, 70^{\circ} \mathrm{C}$ e $105^{\circ} \mathrm{C}$. In: Congresso Brasileiro de Ciência e Tecnologia de Alimentos, 20, 2006, Curitiba. Anais... Curitiba: TECART, 2006. (CD-ROM).

NOGUEIRA, R. I. Secagem e desidratação de frutas e hortaliças. In: NOGUEIRA, R. I. (Ed.). Curso de Processamento de Frutas e Hortaliças. Rio de Janeiro: EMBRAPA, 1992. p. 117-130.

O'BRIEN, R. D. Fats and oils: formulating and processing for applications. London: Crc Press, 2004.

OLIVEIRA, M. N. S. et al. Estágio de maturação dos frutos e fatores relacionados aos aspectos nutritivos e de textura da polpa de pequi (Caryocar brasiliense Camb.). Revista Brasileira de Fruticultura, v. 28, n. 3, p. 58-68, 2006.

OLSON, J. A. Provitamin A function of carotenoids: the conversion of $\beta$-carotene into vitamin A. Journal of Nutrition, v. 119, n. 1, p. 105-108, 1989.

RAMOS, D. M. R. Avaliação das perdas de carotenóides e valor de vitamina A durante a desidratação e a liofilização industrial de cenoura e espinafre. 1991. 106 p. Dissertação (Mestrado em Tecnologia de Alimentos) - Universidade Estadual de Campinas, Campinas, 1991.

RAMOS, M. I. L. et al. Efeito do cozimento convencional sobre os carotenóides pró-vitamínicos "A" da polpa do piqui (Caryocar brasiliense Camb). Boletim do Centro de Processamento de Pesquisa de Alimentos, v. 19, n. 1, p. 23-32, 2001.

RAMOS, M. I. L. Desidratação do piqui (Caryocar brasiliense, Camb.): avaliação do processo através dos teores de carotenóides totais. 1987. 120 p. Dissertação (Mestrado em Ciência dos Alimentos) - Universidade de São Paulo, São Paulo, 1987.

RAMESH, M. et al. Microwave treatment of groundnut (Arachis hypogaea): Extractability and quality of oil and its relation to lipase and lipoxygenase activity. Lebensmittel - Wissenschaft und -Technologie, v. 28, n. 1, p. 96-99, 1995.

RODRIGUEZ-AMAYA, D. B. Nature and distribution os carotenoids in foods. In: CHARALAMBOUS, F. (Ed.). Shelf life studies of foods and beverages: chemical, biological, physical and nutritional aspects. Amsterdam: Elsevier Science, 1993a. p. 547-589.

RODRIGUEZ-AMAYA, D. B. Stability of carotenoids during the storage of foods. In: CHARALAMBOUS, F. (Ed.). Shelf life studies of foods and beverages: chemical, biological, physical and nutritional aspects. Amsterdam: Elsevier Science, 1993b. p. 591-624.

RODRIGUEZ-AMAYA, D. B. Os carotenóides como precursors de vitamina A. Boletim da Sociedade Brasileira de Ciência e Tecnologia de Alimentos, v. 19, n. 4, p. 227-242, 1985.

ROSSELL, J. B; PRITCHARD, J. L. R. Analysis of oilseeds, fats and fatty foods. New York: Elsevier, 1991.

SILVA, E. C.; SOARES, I. C.; HELOU, J. H. Formulações emulsivas contendo óleo de "piqui" (Caryocar brasiliense, Camb.). Cosmetics and Toiletries, v. 5, n. 6, p. 31, 1993.

SILVA, M. T. C.; TURATTI, J. M. Extração de óleo de soja com etanol. Coletânea do Instituto de Tecnologia de Alimentos, v. 21, n. 1, p. 73-89, 1991.

TANGO, J. S.; CARVALHO, C. R. L.; SOARES, N. B. Caracterização física e química de frutos de abacate visando a seu potencial para extração de óleo. Revista Brasileira de Fruticultura, v. 26, n. 1, p. 17-23, 2004. 